\title{
Comparative life cycle assessment of car disc brake systems—case study results and method discussion about comparative LCAs
}

\author{
Katja Tasala Gradin ${ }^{1}$ (D) Anna Hedlund Åström ${ }^{1}$
}

Received: 14 July 2018 / Accepted: 11 October 2019 / Published online: 4 November 2019

(C) The Author(s) 2019

\begin{abstract}
Purpose Two life cycle assessment (LCA) studies comparing a new low-particulate-matter-emission disc brake and a reference disc brake were presented. The purpose was to identify the difference in potential environmental impacts due to a material change in the new disc brake parts. Additionally, the validity was investigated for the simplification method of omitting identical parts in comparative LCA. This was done by comparing the results between the simplified and the full LCA model.

Methods The two disc brakes, new disc brake and reference disc brake, were assessed according to the LCA ISO standards. The ReCiPe 2016 Midpoint (hierarchist) impact assessment method was chosen. Simplifying a comparative LCA is possible, all identical parts can be omitted, and only the ones that differ need to be assessed. In this paper, this simplification was called comparative LCA with an omission of identical parts.

Results and discussion The comparative impacts were analysed over seventeen impact categories. The new disc brake alternative used more resources during the manufacture of one disc compared to the reference disc brake alternative. The shorter life length of the reference disc demanded a higher number of spare part discs to fulfil the same functional unit, but this impact was reduced due to material recycling. The new disc brake impacts were connected primarily to the coating and secondly to the pad manufacture and materials. The validity of the simplification method was investigated by comparing the results of the two LCA models. The impact differences were identical independent of the LCA model, and the same significant impact categories could be identified. Hence, the purpose of the study could be fulfilled, and the simplification was valid.

Conclusions Both LCA models, simplified and full, revealed that the new disc brake had limited environmental advantages. The omission of identical parts made it more challenging to determine if an impact was significant or insignificant. The simplification seemed to be reasonable.
\end{abstract}

Keywords Comparative LCA $\cdot$ Disc brake $\cdot$ LCA simplification method $\cdot$ Material choice impacts $\cdot$ Particulate emissions

\section{Introduction}

Research and published papers on disc brake development are plentiful, e.g. (Federici et al. 2016; Harada et al. 2013; Maleque et al. 2010; Perricone et al. 2017; Verma et al. 2016). These studies investigate particulate emissions generated through

Responsible editor: Wulf-Peter Schmidt

Electronic supplementary material The online version of this article (https://doi.org/10.1007/s11367-019-01704-9) contains supplementary material, which is available to authorized users.

Katja Tasala Gradin

katjag@kth.se

1 Department of Machine Design, Systems and Component Design, KTH Royal Institute of Technology, Brinellvägen 83, 100 44 Stockholm, Sweden wear, noise pollution and other issues related to the use phase. There is, however, a lack of life cycle perspective in disc brake research. To the best of the author's knowledge, no previous published studies are available that investigates impacts from a life cycle perspective, i.e. how the choice of, e.g. materials affects impacts upstream and downstream from the use phase. No studies report, investigate if and how environmental impacts shift due to product development. There are, however, some studies connecting disc brakes and environmental issues. In a study made by Madeswaran et al. (2016), an 'eco-friendly' brake pad is presented but without any impact calculations or life cycle considerations. The master thesis by Andersson and Dettmann (2013) about optimising brake disc production does consider several different impact categories. However, the study scope is limited to production. In the study done by Eddy et al. (2015), a disc brake development is used as a case study to test a predictive modelling for material selection. Eddy 
and colleagues made a significant point about materials being of substantial importance for the sustainability level of the product. However, no actual life cycle assessment (LCA) results are revealed.

As recognised, cars contribute to both exhaust and nonexhaust emissions (Grigoratos and Martini 2015; Kupiainen 2007). Exhaust or tailpipe emissions are produced by the combustion of fuel or wear in a vehicle engine, while non-exhaust emissions are all other emissions from a vehicle (Kupiainen 2007). Non-exhaust emissions, e.g. particulates, are a known issue with significant impact on plant, animal and human health (Abbasi et al. 2013). The brake system is one of the primary sources of non-exhaust particle emissions (Grigoratos and Martini 2015). Even though non-exhaust emissions such as brake particulates are not regulated yet (Grigoratos and Martini 2015; Kupiainen 2007) and due to the environmental objective to reduce air pollution (IIASA, 2016), there is an interest to decrease the amount of particulate generated through braking. New materials are tested in both brake pads and discs. Tests indicate that the amount of particulate matter decreases when, among other factors, the materials show an increased resistance to wear (Federici et al. 2016; Wahlström et al. 2017). The Lowbrasys project (LOWBRASYS 2017), presented a new disc brake with modification of pad and disc materials. Internal project test exhibited a $16 \%$ decrease of particulate matter (PM) formation caused by braking. The reduced wear also increased the life length of the disc compared to a reference disc. Hence, PM formation decreased during the use phase. However, other resources, raw materials and processes are used upstream, and the end-of-life treatment should be adapted to manage the new disc brake materials. From a life cycle perspective, the gain in the use phase has consequences in other life cycle phases, as shown in vehicle LCA studies, e.g. (Hawkins et al. 2013; Notter et al. 2010).

This paper presents two types of comparative LCA studies of the new disc brake and the reference disc brake: a full LCA study and a comparative LCA with omitted identical parts. The primary purpose of this study is to identify the differences in environmental impacts of the disc brakes in a life cycle perspective. Beyond answering how the environmental life cycle impacts are affected by the disc brake material change, the secondary objective of this paper is to investigate and discuss the validity of simplifications in comparative LCA. The results of the full LCA are compared against the results of the comparative LCA with omitted parts.

\subsection{Comparative LCA with an omission of parts}

It is agreed upon in the LCA research society that most LCA studies are in fact comparative LCAs, comparing some alternative product-systems, or comparing an existing product-system with a proposed redesign, as stated by, e.g. (Heijungs et al. 2017). In comparative LCA two or more different products are compared which have the same or similar function. According to, e.g. the ILCD Handbook (European Commission 2010) and Finnveden (1999), it is possible to simplify a comparative LCA. All parts that are identical between the compared products can be omitted, and only those that differ need to be assessed. The parts could be, e.g. life cycle phases, materials or processes. It is common in waste LCAs to exclude all life cycle phases before the end-of-life stage. This is sometimes called the 'zero-burden assumption'- -suggesting that the waste carries none of the upstream burdens into the waste management system (Ekvall et al. 2007). This simplification is justified by claiming that the previous life cycle phases are identical for the compared products and can, therefore, be omitted. In this paper, this simplification is called comparative LCA with an omission of parts.

Simplifications can drastically reduce the efforts required for an LCA study. It reduces the practical weakness of LCA through the lesser need for time-consuming analysis, data gathering and uncertainties (Tillman et al. 1994). Simplification could, therefore, be of critical value for an LCA study. The omission of parts is an appealing move, though possible consequences of the assumed method should be questioned and examined. In waste LCAs, it is essential to reflect on the question of how the previous life cycle is affected by the product's end-of-life destiny. For example, waste management of end-of-life vehicles, if the owner of a car knows that the car parts will be reused and recycled, would the owner decide to waste the car sooner than if it was known to be landfilled and downcycled? The uncertainty of omission of upstream processes for an end-of-life vehicle LCA was briefly discussed in an earlier study (Gradin et al. 2013).

The omission of identical parts, called simplification in this paper, can intuitively be perceived as evident. However, the assumption is only valid if the omitted parts are unaffected. It is not always obvious what is constant between systems. There is a risk that omissions are used out of habit. Therefore, it should be examined and questioned systematically. Three pitfalls are identified: (i) creates an assessment blind spot, (ii) decreases the analyses of impact significance and (iii) prevents hot spot analysis. First of all, significant impacts might be overlooked. This concern is mainly of significance if there are no or few previous studies of a particular product, as in this case with disc brakes. There is a risk of 'straining gnats and swallowing camels'; potential environmental impacts in the excluded parts might surpass the assessed parts by magnitudes. Secondly, it will offer only a comparing result, which is less revealing than a full LCA. It is difficult to evaluate whether a difference is small or large, i.e. $1 \mathrm{~kg}$ can be significant ( $2 \mathrm{~kg}$ compared to $3 \mathrm{~kg}$ in total) or insignificant ( $999 \mathrm{~kg}$ compared to $1,000 \mathrm{~kg}$ in total). Thirdly, a hotspot analysis is prevented since it is unknown how much the omitted parts contribute to the impact (Hauschild et al. 2018). The inaccurate information might lead to suboptimal recommendations of actions and decisions. 


\section{Methods}

The two disc brakes were assessed with guidance of the ISO 14040:2006 standard (ISO 2006). The life cycle impacts of the new disc brake were compared to the life cycle of a reference disc brake, i.e. from the cradle to the grave, including processes from material extraction until waste management. In this paper, the life cycle environmental impacts of the products were calculated in the software SimaPro version 9.0.0.47 (PRé Consultants 2019).

\subsection{Case study}

In the LOWBRASYS (LOW environmental impact BRAke SYStem) project (LOWBRASYS 2017), one of the project objectives was to develop a new disc brake that reduces particulate generation during braking. The wear rate was reduced by changing the contact pair regarding the material composition and part coatings. The mix of the friction material in the pads was modified, a disc coating was added, and paired to minimise particulate formation. Wear testing, by the project partners, indicates a $16 \%$ decrease in particulate formation.

\subsubsection{Goal and scope}

The goal of this study was to categorise the differences in environmental impacts between the two options of disc brakes. Therefore, it was of interest to analyse other impacts than particulate emissions. Hence, all seventeen impact categories calculated by the model were studied.

The scope of the study includes the complete life cycle for both disc brakes, which were used in medium-sized petrol passenger cars in the EU. The assessed brakes were assembled in identical cars; the main difference between the two brakes was the different materials in and on the disc and pads. The time scope was the present and up to 100 years as considered by the hierarchist perspective (see further down for more on the choice of the impact assessment method). The full LCA system boundary includes raw material extraction, manufacturing, transport of resources and products, use, and end-of-life management of the disc brakes. The system boundaries for the full LCA and the comparative LCA with omitted parts are defined in detail in the inventory section. The assembly of the disc brake into the car was cut-off due to insignificant impact contribution.

When comparing two products, it is essential to define a functional unit to which both products can be referenced. For example, it is critical when comparing the two different disc brake options to find a functional unit so that the compared products can be reasonably and fairly related. The primary function of a disc brake is to slow down or to keep a constant speed of a car by transforming kinetic energy into frictional heat. The braking must be done securely and efficiently; the performance security of the product is critical. The braking performance of the two disc brakes is equivalent; the performance was tested and presented in Wahlström et al. (2017). The functional unit was defined as the deceleration of a car during the lifetime of the car. The omission of parts is possible since this is a comparative study of two disc brakes, and parts not affected by the disc brake change can be excluded (Tillman et al. 1994) (Fig. 1).

The scope of the use phase was set to the lifetime of a car, i.e. $240,000 \mathrm{~km}$. The functional unit is the unit to which all calculated environmental impacts are referenced. The chosen lifetime was based on internal discussions within the project and might seem long for an average car. As stated by Capitano (2015), in regard to PM emissions, increasing the use phase length would have the effect of magnifying the use phase's importance, and diminishing the impact of the other phases. The sensitivity of the choice of the lifetime was tested. The reference flows for both disc brakes are listed in Table 1.

In this study, the ReCiPe 2016 Midpoint (hierarchist) impact assessment method was chosen to transform the long list of life cycle inventory results, into a limited number of category indicator results. These category indicator results express the relative severity of one product-system to another product system within one impact category. The hierarchist perspective is a consensus model, as often encountered in scientific models, and this is often considered to be the default model (PRe Consultants 2017). The ReCiPe Midpoint method delivers seventeen impacts categories; the categories are listed in Table 3. Since there is a lack of previous LCA disc brake studies, it is difficult to know what aspects of the life cycle and impact categories are of consequence. Because of this, all impact categories calculated by the method were investigated, and some categories were chosen for further scrutiny.

The study was prospective, i.e. the aim was to investigate the effects of the material changes (Tillman 2000). To describe the product system and its environmental impacts, an attributional approach (a.k.a. accounting approach) was chosen (Finnveden et al. 2009). The choice of data was mainly average. However, for transport distances marginal data was chosen, i.e. the longest route between the sites suggested by Google maps (Google 2018). Primary data were collected from project members and cooperating companies. When data were missing, general SimaPro processes were used. General SimaPro processes give indications about where potential significant environmental impacts might be located.

\subsubsection{Assumptions and limitations}

The database and inventory in SimaPro concerning particulate emissions are based on non-specific particulates. Thus, the impacts of the particulate emissions might be underestimated since the toxicity of for example nanomaterials, significantly depending on for example particle size and size distribution, 
Fig. 1 Flow chart describing assessed and omitted parts

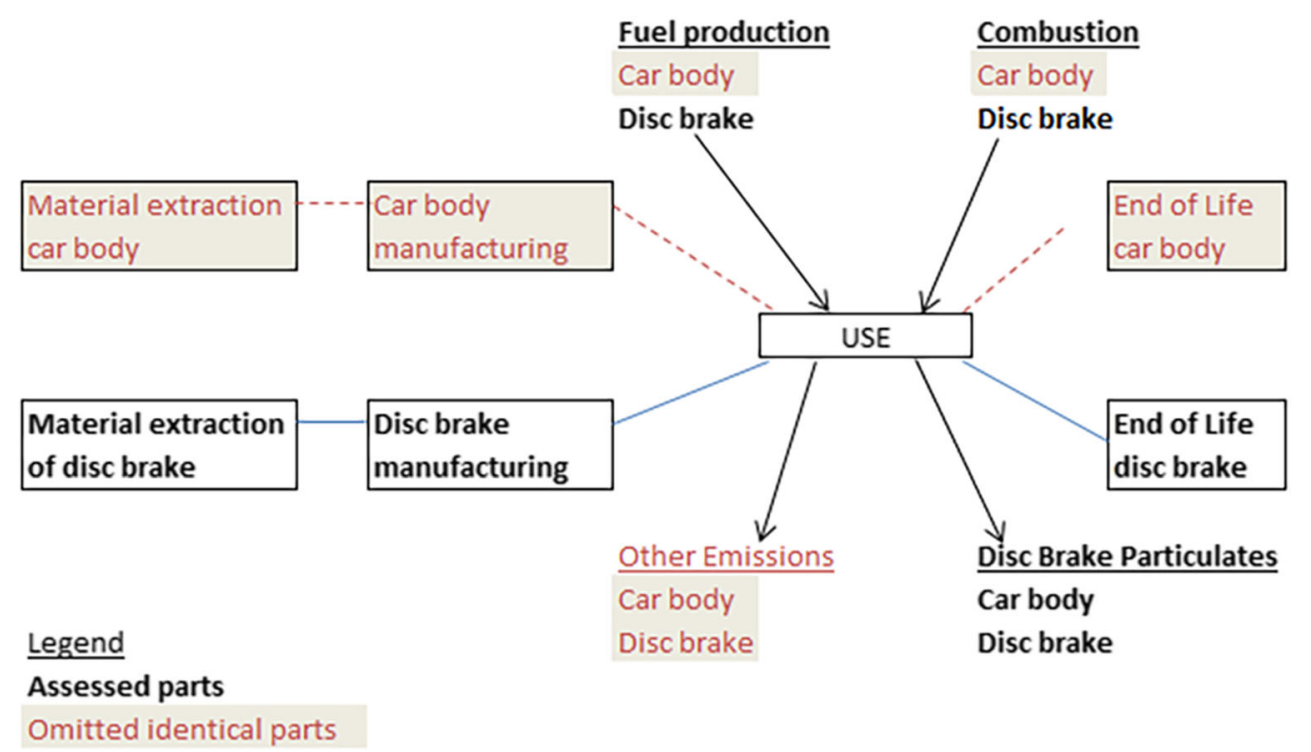

agglomeration state, shape, crystal structure, chemical composition, surface area, surface chemistry, surface charge and porosity (Oberdörster et al. 2005).

To protect the Intellectual Property of the involved companies, it is not possible to reveal details about the materials included in the parts and processes involved in manufacturing. Consequently, it is not possible to publish the detailed data inventory of the bill of materials and more (see the Electronic Supplementary Material (ESM)). It is noted that the lack of accessible data entails a severe threat to the transparency of this study.

In some cases materials used, e.g. the friction mix are not included in any of the SimaPro databases; in these cases, materials as close as possible to the original material were chosen. One specific limitation was the lack of data in the databases on tungsten carbide. The material was used in the new disc powder coating. In this LCA model, available data estimate on tungsten carbide environmental impact was used from the IDEMAT2017 database, process 'Idemat2018 Tungsten Carbide estimate'.

Since the fuel reduction value (FRV) is commonly used in vehicle component LCAs a FRV calculation was presented (Koffler and Rohde-Brandenburger 2010; Ridge 1998; Schmidt et al. 2004), and the fuel consumption of the disc brake was calculated.

Table 1 Reference flow for reference and new disc brake to deliver the performance described by the functional unit

\begin{tabular}{lll}
\hline & Reference disc brake & New disc brake \\
\hline Pads & 14 & 16 \\
Discs & 2.5 & 1 \\
\hline
\end{tabular}

\section{Life cycle inventory}

One brake corner of a car was assessed, consisting of two friction material pads and a disc. The complete life cycles are presented in the flowcharts representing the reference disc brake in Fig. 2, and the new disc brake in Fig. 3. Red squares mark the system boundaries with inputs and outputs represented by arrows, e.g. spare parts that are needed during the use phase. Note that the assembly is cut-off from the assessment, but included in the figures to present a complete life cycle. A similar LCA inventory is naturally also described in a previous conference paper presenting a first assessment of the disc brakes (Gradin and Hedlund-Åström 2018).

The same process data is listed for both the full LCA and the comparative LCA inventory, but the comparative LCA only uses the parts that are dissimilar between the disc brakes. The processes that are different between the disc brakes are coloured in Figs. 4 and 5. The red squares indicate the system boundary, i.e. the assessed processes for each product. The parts that are omitted are a collection of materials in the friction mix, the pad manufacturing, the primary disc material and production, assembly and some transports. However, since there is a need to produce a different number of spare parts, the full LCA models are used in the spare part life cycles.

\subsection{Material extraction and manufacture}

The friction mix differs between the reference pad and the new pad. The materials mixed into the friction pad are a complex mix of resins, metals and polymers. To protect the immaterial right of the pad manufacturer, it is not possible to specify the material mix further. The materials and additives are extracted, mixed, pressed, heated and processed. The friction mix is 


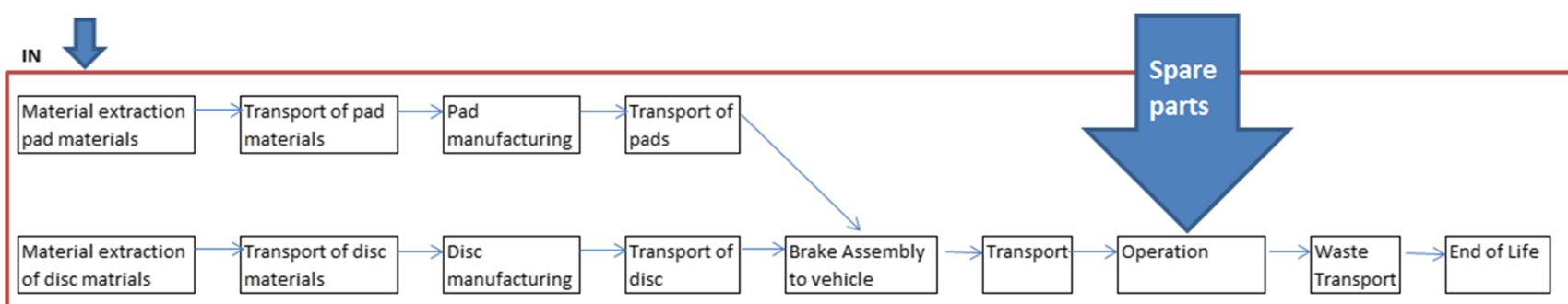

OUT

Fig. 2 Reference disc brake flowchart and the system boundary represented as an outer square

attached to a pad back-plate. The manufacturing is located in Bad Camberg, Germany. However, the manufacturing processes for both pads are identical; therefore, the processes can be omitted in the simplified LCA model. The finished brake pad is transported to the car manufacturer for assembly into the car. Both pad alternatives have the same mass.

Both the new and the reference discs are made out of $100 \%$ recycled cast iron. The discs are cast in a sand mould, and the parts are trimmed in turning processes to reach specified dimensions, and balanced. The disc is finally painted with protective paint. The reference disc is uncoated while the newly developed disc is coated with a thermal spray powder that is carbide-based. The discs to be coated are transported from Dabrowa, Poland, to Szada, Hungary, while the uncoated discs are transported directly to the car manufacturer in Germany. Raw materials for the disc coat are extracted and transported to Goslar, Germany, for powder production. The finished thermal powders are then transported to Szada, Hungary; $450 \mathrm{~g}$ of powder are used for each disc coating. The coating process is WC-Co-Cr thermal spraying; the efficiency is about $23 \%$, i.e. $350 \mathrm{~g}$ of powder are discarded. The amount of needed powder and the efficiency does vary, in this case study, marginal data, i.e. a 'worst case' is chosen to investigate the potential impact of the powder materials. The coated discs are also distributed to the car manufacturer for assembly into the car. The finished discs have a mass difference of $100 \mathrm{~g}$ due to the added coating on the new disc. The mass of the reference disc brake is $7.058 \mathrm{~kg}$, and the mass of the new disc brake is $7.158 \mathrm{~kg}$, the mass difference is accounted for in the operation process.

\subsection{Use phase}

Many processes are identical between the disc brake life cycles. The differences are the material mix in the friction pads, an additional coating of the new disc and most notably the use phase aspects. As described in a previous section, the functional unit is set to 'deceleration of a car during the lifetime of the car'; this is assumed to be $240,000 \mathrm{~km}$.

To model the use phase the SimaPro process 'Transport, passenger car, medium size, diesel, EURO $5\{R E R\} \mid$ transport, passenger car, medium size, diesel, EURO $5 \mid$ Alloc Def, $U$ ' was used and modified. Omitted from the use phase assessment were the car body, road, maintenance and all other use phase impacts than non-exhaust emissions due to the disc brake, fuel production and combustion due to the disc brake. The omission is possible since this is a comparative study of two disc brakes, and parts not affected by the disc brake change can be excluded (Tillman et al. 1994) (see Fig. 1). The fuel production and consumption are calculated based on the disc brake mass while the disc brake emissions are based on the total car mass. Thereby, the issue of the mass non-scalability of disc brake particulate emissions is avoided.

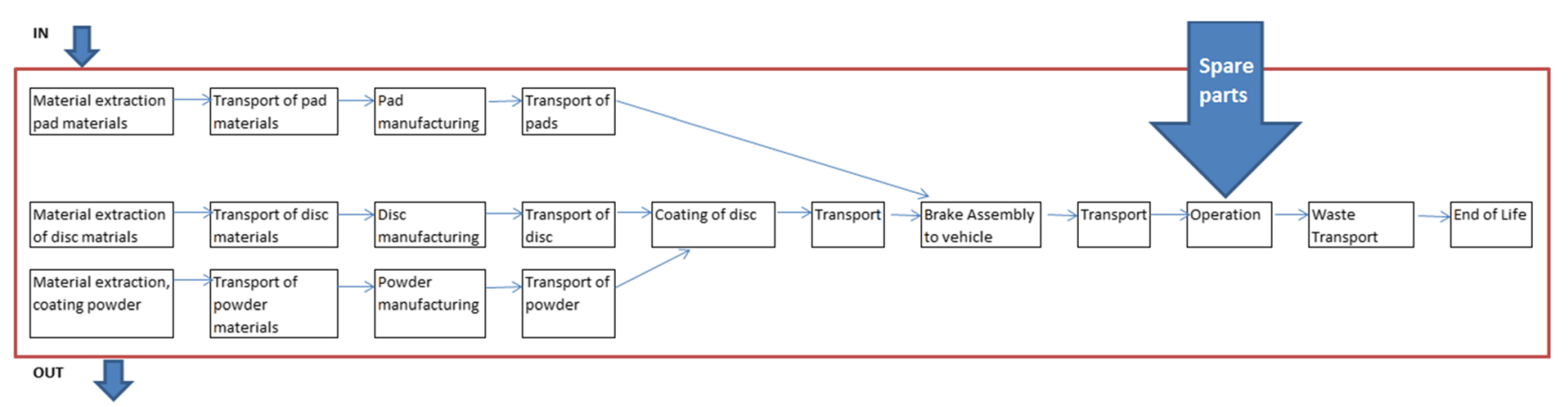

Fig. 3 New disc brake flowchart and the system boundary represented as an outer square 


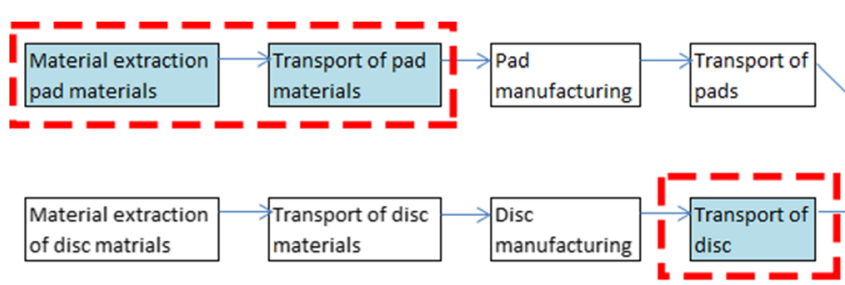

Fig. 4 The flowchart of the reference disc brake. In the comparative LCA, the coloured process boxes framed by the dashed red system boundary indicate that the processes differ between the disc brakes

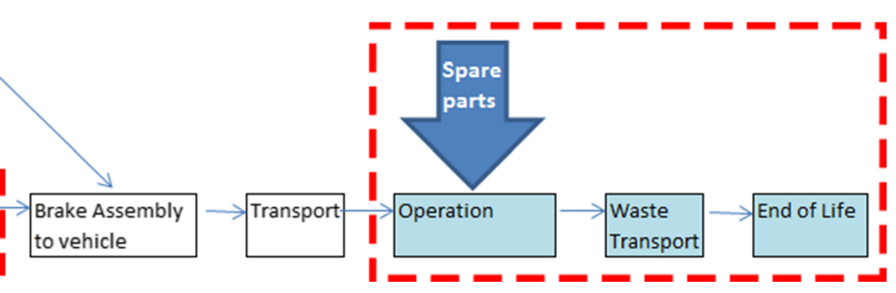

while white the process boxes outside indicate processes that are identical between the disc brakes. Hence, the system boundary includes only the processes that differ between the disc brake systems
The amount of production and combustion of petrol is due to the disc brake mass. The petrol consumption for both brake systems was determined based on the FRV calculation, with 0.2 and 0.5 per $100 \mathrm{~kg}$ and $100 \mathrm{~km}$ (Ridge 1998). The petrol consumption per component was calculated with $240,000 \mathrm{~km}$ of use. Additionally, the $\mathrm{CO}_{2}$ and $\mathrm{SO}_{2}$ emissions during the combustion of petrol are calculated based on stoichiometric relations. See calculations in the ESM.

The petrol in the process were modelled through 'Petrol, low-sulfur \{Europe without Switzerland $\} \mid$ market for $\mid$ Alloc Def, $U$ ' and 'Petrol, low-sulfur $\{\mathrm{CH}\} \mid$ market for $\mid$ Alloc Def, $U$ ', and the disc brake emissions were modelled through 'Brake wear emissions, passenger car $\{G L O\} \mid$ market for | Alloc Def, $U$ '. The mass of particulates emitted per vehicle $\mathrm{km}$ (vkm) is according to Ntziachristos and Boulder (2016), i.e. $7.6 \mathrm{mg} / \mathrm{vkm}$. It is noted that there are many studies reporting a wide variety of mass $/ \mathrm{km}$ results, this is due to a lack of common driving cycles for testing and that many variables affect the emissions, e.g. weather (Perricone et al. 2019). The average amount, used in Ecoinvent 3, based on Ntziachristos and Boulder's (2016) results seem to be acceptable, and match the project results.

The life length of the different parts depends on wear resistance. Additional testing by the car manufacturer shows that the lifetime of the new disc is at least as long as the lifetime for the car while the lifetime of the reference disc is relatively shorter. Over the lifetime of the car, one new disc is needed while 2.5 reference discs are needed during the same period. During the lifetime of the car, 14 reference pads are needed, while during the same time 16 new disc brake pads are needed. The reference flow for reference and new disc brake is presented in Table 1. The higher number of new pads is due to a higher wear rate caused by the hard coating. The needed numbers of additional parts to be manufactured for spare parts are presented in Table 2. The spare parts are modelled as additional full life cycles connected to the life cycle of the primary disc brake.

\subsection{End-of-life phase}

The discarded disc brake parts are assumed to be disassembled, and waste managed separately. The reference disc is material recycled ( $90 \%$ of mass). The coated new disc is also recycled (90\% of mass). However, the coat materials are assumed to be lost in the recycled cast iron melt. The friction materials of the reference brake pads and the new brake pads are incinerated with energy recovery while the pad back-plate is recycled. The assumption about the rate of material recycling of the disc brakes might be considered an overly optimistic scenario, but in this case, the model is based on internal project data.

\subsection{Transport}

The disc brake parts are manufactured at different sites across the EU. The casting of the discs is in Dabrowa, Poland. The thermal spraying of the new disc is done in Szada, Hungary, while the metal powder is produced in Goslar and Laufenburg, Germany. The pads are manufactured at a site in Bad Camberg, Germany. All parts are transported to the car
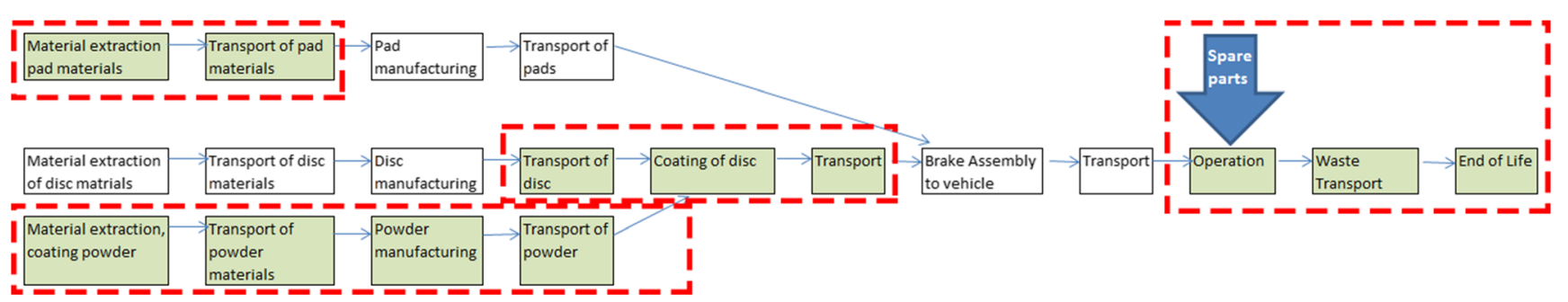

Fig. 5 The flowchart of the new disc brake. In the comparative LCA, the coloured process boxes framed by the dashed red system boundary indicate that the processes differ between the disc brakes while the

white process boxes outside indicate processes that are identical between the disc brakes. Hence, the system boundary includes only the processes that differ between the disc brake systems 
Table 2 Spare parts needed during the functional unit time

\begin{tabular}{lll}
\hline Spare parts & Reference disc brake & New disc brake \\
\hline Pads & 12 & 14 \\
Discs & 1.5 & 0 \\
\hline
\end{tabular}

manufacturer site in Saarlouis, Germany, to be assembled on a car. All transports within the EU are assumed to be done by a large EURO 5 lorry. Additional transports are raw materials moved from the extraction site to the production site; these transports are mainly included in the SimaPro materials processes. Transport of waste, i.e. production waste and discarded disc brakes are assumed to be $10 \mathrm{~km}$.

\section{Results and interpretation}

In this section, the results and interpretation of both LCA models are presented and compared. First, the petrol consumption connected to the disc brake is calculated through FRV calculations. The lower petrol amount is used in the presented LCA results and additional results based on the higher petrol amount are found in Supplementary materials.

FRV calculations and the results of the full LCA study are presented. Then, followed by the results of the comparative LCA with omitted parts are shown. The results of both models are compared and analysed. Finally, sensitivity analyses are presented.

\subsection{FRV calculation}

The petrol consumption of the car for both brake systems was determined based on the FRV calculation, with a low factor of 0.2 and a high factor of 0.5 per $100 \mathrm{~kg}$ and $100 \mathrm{~km}$ (Ridge 1998). The petrol consumption per component was calculated with 240,000 km of use; please see calculations in the ESM.

There was an insignificant difference between the two disc brakes since the mass difference was only $100 \mathrm{~g}$. If the lower factor $(0.2)$ was used, the petrol consumption was 33.88 and 34.361 for each component, where the higher amount is due to the slightly higher mass of the new disc brake. If the higher factor (0.5) was used, the lifetime petrol consumption was 84.70 and 85.901 respectively. The following results are calculated with factor 0.2 , i.e. the lower petrol consumption. For the results calculated with the higher factor 0.5 , i.e. the higher petrol consumption, please see the ESM.

\subsection{Results of the full LCA}

The differences in impacts of the two disc brakes were distributed over 17 impact categories (see Table 3). The contribution analysis showed that there were some significant differences, e.g. there was a significantly higher impact by the new disc brake in the impact categories of 'ionizing radiation' and

Table 3 The impacts caused by the disc brakes presented in seventeen impact categories

\begin{tabular}{|c|c|c|c|c|c|}
\hline Impact category & Unit & Reference disc Brake & New disc brake & Difference & Diff. $\%$ \\
\hline Global warming & $\mathrm{kg} \mathrm{CO}_{2}$ eq & 90 & 120 & 30 & $33 \%$ \\
\hline Stratospheric ozone depletion & $\mathrm{kg} \mathrm{CFC11} \mathrm{eq}$ & 0.000069 & 0.000071 & 0.000002 & $3 \%$ \\
\hline Ionizing radiation & $\mathrm{kBq} \mathrm{Co}-60 \mathrm{eq}$ & 19.0 & 30.2 & 11.2 & $59 \%$ \\
\hline Ozone formation, human health & $\mathrm{kg} \mathrm{NO}_{\mathrm{x}} \mathrm{eq}$ & 0.2 & 0.3 & 0.04 & $21 \%$ \\
\hline Fine particulate matter formation & $\mathrm{kg} \mathrm{PM}_{2.5}$ eq & 0.9 & 0.8 & -0.1 & $-9 \%$ \\
\hline Ozone formation, terrestrial ecosystems & $\mathrm{kg} \mathrm{NO}_{\mathrm{x}}$ eq & 0.2 & 0.3 & 0.04 & $20 \%$ \\
\hline Terrestrial acidification & $\mathrm{kg} \mathrm{SO}_{2} \mathrm{eq}$ & 0.6 & 0.7 & 0.1 & $14 \%$ \\
\hline Freshwater eutrophication & $\mathrm{kg} P$ eq & 0.1 & 0.1 & 0.02 & $30 \%$ \\
\hline Terrestrial ecotoxicity & $\mathrm{kg} 1.4-\mathrm{DCB} \mathrm{e}$ & 41.8 & 35.1 & -6.7 & $-16 \%$ \\
\hline Freshwater ecotoxicity & $\mathrm{kg} 1.4-\mathrm{DCB} \mathrm{e}$ & 14.9 & 13.4 & -1.6 & $-10 \%$ \\
\hline Marine ecotoxicity & $\mathrm{kg} 1.4-\mathrm{DBC} \mathrm{e}$ & 88.9 & 75.9 & -12.9 & $-15 \%$ \\
\hline Human carcinogenic toxicity & $\mathrm{kg} 1.4-\mathrm{DBCe}$ & 46.0 & 29.9 & -16.2 & $-35 \%$ \\
\hline Human non-carcinogenic toxicity & $\mathrm{kg} 1.4-\mathrm{DBC} \mathrm{e}$ & 36532 & 32294 & -4238 & $-12 \%$ \\
\hline Land use & $\mathrm{m} 2 \mathrm{a}$ crop eq & 2.84 & 2.80 & -0.04 & $-1 \%$ \\
\hline Mineral resource scarcity & kg Cu eq & 1.53 & 5.30 & 3.77 & $246 \%$ \\
\hline Fossil resource scarcity & kg oil eq & 47.85 & 60.90 & 13.06 & $27 \%$ \\
\hline Water consumption & $\mathrm{m} 3$ & 214.86 & 207.09 & -7.77 & $-4 \%$ \\
\hline
\end{tabular}

Impact categories in bold indicate a significantly higher impact, and the italics indicate a significantly lower impact caused by the new disc brake compared to the reference disc brake. The last columns display the difference of the impact of the new disc brake compared to the reference disc brake 
'mineral resource scarcity'. Eight of the 17 impact categories displayed a decrease of impact and for one category 'human carcinogenic toxicity' the impact decrease was significant.

Process contributions in the 'ionizing radiation' category for the new disc brake were linked to the coating of the disc. The primary impacts were connected to the thermal spraying of the new disc, i.e. Hungarian electricity mix and liquid oxygen. The Hungarian electricity mix was the energy used for the thermal spraying, and impacts from the liquid oxygen were connected to the energy (average European electricity mix) required to produce the oxygen. Half of the Hungarian electricity mix is imported fossil fuel, and the other half is domestic produced energy mainly through nuclear power and fossil fuel (IEA 2016). In general, the impacts caused by both discs originated from the cast iron and manufacturing of the discs. These specific disc impacts were higher for the reference disc brake due to the need for 1.5 discs more compared to the new disc brake. However, due to the favourable effects of cast iron recycling the impact connected to the new coating were higher than the impact connected to the disc.

In the 'mineral resource scarcity' impact category, the tungsten carbide used in the new disc coating gave a notable impact by about $50 \%$ (2.83 $\mathrm{kg} \mathrm{Cu}$ eq.) of the total life cycle impact. Similarly, the impact of the additional reference disc spare part did have a notable impact due to manufacturing and use of cast iron but was decreased due to cast iron recycling. Additionally, it was observed that the pad manufacturing and materials had a significant contribution to this category.

The four categories 'fine PM formation', 'terrestrial ecotoxicity', 'marine ecotoxicity' and 'human noncarcinogenic toxicity' were primarily only linked to the brake wear emissions. The impact caused by the new disc brake is slightly lower due to the reduced amount of PM formation.

The 'human carcinogenic toxicity' was linked to the materials and manufacturing of the cast iron disc. Hence, due to the more substantial amount of reference discs, the impact was higher. The recycling of cast iron lowered the high impact, but the manufacturing of the disc had a significant impact.

It became clear that the new disc brake had limited advantages. The new disc brake alternative used more resources during the manufacture of one disc compared to the reference disc brake. The shorter life length of the reference disc resulted in a higher demand on the number of spare part discs to fulfil the same functional unit, but this impact was reduced due to material recycling. The primary contributing impacts of reference disc brake materials and processes were linked to the cast iron, the manufacturing of the discs, manufacture of pads and materials in the pads friction mix, such as copper and brass. The contributing impacts of the new disc brake were connected primarily to the coating and secondly to the pad manufacture and materials.

\subsection{Results of the comparative LCA with omitted parts}

A study of the two disc brakes was also conducted using the comparative LCA with omitted parts. Therefore, all materials, processes and life cycle parts that were identical between the two disc brakes were eliminated and not assessed in this study. The results, presented in the same way as for the full LCA, are shown in Table 4 . There was a significantly higher environmental impact by the new disc brake in the two impact categories of 'ionizing radiation' and 'mineral resource scarcity'. Eight of the 17 impact categories displayed a decrease of impact and for one category 'human carcinogenic toxicity' the impact decrease was significant.

According to the comparative results, the impacts in the 'ionizing radiation' category for the new disc brake were linked to the coating process, i.e. the thermal spraying of the new disc in this case due to a Hungarian electricity mix and impacts due to the production of liquid oxygen.

The primary material processes impacting the 'mineral resource scarcity' category were tungsten carbide and cobalt. The tungsten carbide gave a significant impact by $52 \%(2.83 \mathrm{~kg} \mathrm{Cu}$ eq.). The significant contributors for the reference alternative were connected to the pad materials and manufacture, but these impacts were significantly lower than the coating material impacts.

The four categories 'fine PM formation', 'terrestrial ecotoxicity', 'marine ecotoxicity' and 'human noncarcinogenic toxicity' were primarily only linked to the brake wear emissions. The impact caused by the new disc brake is slightly lower due to the reduced amount of PM formation.

The 'human carcinogenic toxicity' impact category were linked to the materials and manufacturing of the cast iron disc. Hence, due to the more substantial amount of reference discs, the impact was higher than for the new alternative.

The comparative assessment shows that the new disc brake had significant impacts on many of the 17 impact categories. The new disc brake used, e.g. fossil energy for the disc coating and energy demanding liquid oxygen production. The reference disc and spare part discs did have a significant impact, with the cast iron contributing to over $54 \%$ of the impact in the 'human carcinogenic toxicity' category. The impact was however compensated with the recycling of the iron.

\subsection{Comparing the results}

When comparing the results of the two LCA models, differences were expected in the aggregated environmental impact for each disc brake. The difference was due to the omitted parts in the comparing LCA, i.e. the impacts of the disc brakes in the simplified LCA were lower. However, it was not the individual impacts that were of interest but the comparison of differences in impact between the disc brakes, in this study. Comparing the results revealed that the same impact 
Table 4 The results of the comparative LCA with omitted parts

\begin{tabular}{|c|c|c|c|c|c|}
\hline Impact category & Unit & Reference disc brake & New disc brake & Difference & Diff. $\%$ \\
\hline Global warming & $\mathrm{kg} \mathrm{CO}_{2}$ eq & 78 & 108 & 30 & $38 \%$ \\
\hline Stratospheric ozone depletion & kg CFC11 eq & 0.000063 & 0.000066 & 0.000002 & $4 \%$ \\
\hline Ionizing radiation & kBq Co-60 eq & 14.3 & 25.5 & 11.2 & $79 \%$ \\
\hline Ozone formation, human health & $\mathrm{kg} \mathrm{NO}_{\mathrm{x}}$ eq & 0.2 & 0.2 & 0.04 & $23 \%$ \\
\hline Fine particulate matter formation & $\mathrm{kg} \mathrm{PM}_{2.5}$ eq & 0.9 & 0.8 & -0.1 & $-9 \%$ \\
\hline Ozone formation, terrestrial ecosystems & $\mathrm{kg} \mathrm{NO}_{\mathrm{x}}$ eq & 0.2 & 0.2 & 0.04 & $22 \%$ \\
\hline Terrestrial acidification & $\mathrm{kg} \mathrm{SO}_{2}$ eq & 0.5 & 0.6 & 0.1 & $15 \%$ \\
\hline Freshwater eutrophication & $\mathrm{kg} \mathrm{P}$ eq & 0.1 & 0.1 & 0.02 & $33 \%$ \\
\hline Terrestrial ecotoxicity & $\mathrm{kg} 1.4-\mathrm{DCB}$ e & 41.7 & 35.1 & -6.7 & $-16 \%$ \\
\hline Freshwater ecotoxicity & $\mathrm{kg} 1.4-\mathrm{DCB} \mathrm{e}$ & 13.1 & 11.5 & -1.6 & $-12 \%$ \\
\hline Marine ecotoxicity & $\mathrm{kg} 1.4-\mathrm{DBC} \mathrm{e}$ & 86.3 & 73.4 & -12.9 & $-15 \%$ \\
\hline Human carcinogenic toxicity & $k g$ 1.4-DBCe & 31.7 & 15.5 & -16.2 & $-51 \%$ \\
\hline Human non-carcinogenic toxicity & $\mathrm{kg} 1.4-\mathrm{DBC} \mathrm{e}$ & 35310 & 31072 & -4238 & $-12 \%$ \\
\hline Land use & m2a crop eq & 2.22 & 2.18 & -0.04 & $-2 \%$ \\
\hline Mineral resource scarcity & kg Cu eq & 1.67 & 5.44 & 3.77 & $225 \%$ \\
\hline Fossil resource scarcity & kg oil eq & 45.29 & 58.34 & 13.06 & $29 \%$ \\
\hline Water consumption & $\mathrm{m} 3$ & 156.27 & 148.50 & -7.77 & $-5 \%$ \\
\hline
\end{tabular}

Impact categories in bold indicate a significantly higher impact, and the italics indicate a significantly lower impact caused by the new disc brake compared to the reference disc brake. The last columns display the difference of the impact of the new disc brake compared to the reference disc brake

categories were identified as having increased impact due to the new disc brake. In addition, the impact categories with a noteworthy decrease in impact were also the same. There was no difference between the full LCA results and in the comparative results, i.e. the 'difference' column in Tables 3 and 4. However, the percentile difference was different due to the total being different. The same significant impact categories and processes could be identified regardless of the LCA model.

\subsection{Sensitivity analysis}

The relatively high lifetime assumption for the car carrying the disc brake was analysed - the life length of the car influence the number of spare parts used, i.e. shorter time-less spare parts and longer time - more spare parts. The previously often used assumption of $150,000 \mathrm{~km}$ based on educated guess represents an underestimated value and should be increased (Weymar and Finkbeiner 2016). In this study, the lifetime was varied between 150,000 km (Hawkins et al. 2012), $240,000 \mathrm{~km}$ (the current case study) and 330,000 km (marginal case). The number of spare parts was adjusted with the changed lifetime (see Table 5).

The negative number $(-0.4)$ of new discs in the $150,000 \mathrm{~km}$ lifetime was due to the long lifetime of the disc. To cover $150,000 \mathrm{~km}$ of life only 0.6 discs were needed.

The longer lifetime had no environmental enhancement effect, concerning the new disc brake, on the eight impact categories 'global warming', 'ionizing radiation', 'ozone formation, human health', 'ozone formation, terrestrial ecosystems', 'terrestrial acidification', 'fossil resource scarcity', 'freshwater eutrophication' and 'mineral resource scarcity'. This means that the higher impact of the new disc brake did not diminish compared to the reference disc brake. The relation was similar to the 'ionizing radiation' impacts illustrated in Fig. 6.

The impacts in the 'fine particulate matter formation', 'terrestrial ecotoxicity', 'freshwater ecotoxicity', 'marine ecotoxicity', 'human carcinogenic toxicity' and 'human noncarcinogenic toxicity' categories developed similarly. The impacts in the six categories, the relative impact between the disc brake impacts, were not changed with a longer lifetime. The relation is illustrated by 'human carcinogenic toxicity' in Fig. 7. The reference disc brake impacts, in these categories, were higher than for the new alternative, regardless of distance.

For the impact categories 'stratospheric ozone depletion', 'land use',and 'water consumption', the impacts were lower for the new disc brake for the shorter distances. But for distances over $330,000 \mathrm{~km}$, the new disc brake impact surpassed the ref

Table 5 Lifetime adjusted spare part number for the disc brake alternatives

\begin{tabular}{lllll}
\hline Lifetime $(\mathrm{km})$ & Reference pad & Reference disc & New pad & New disc \\
\hline 150,000 & 7.5 & 0.9 & 8.8 & -0.4 \\
240,000 & 12 & 1.5 & 14 & 0 \\
330,000 & 16.5 & 2.1 & 19.3 & 0.4 \\
\hline
\end{tabular}


Fig. 6 The 'ionizing radiation' impact difference increased with a longer lifetime

\section{lonizing radiation}

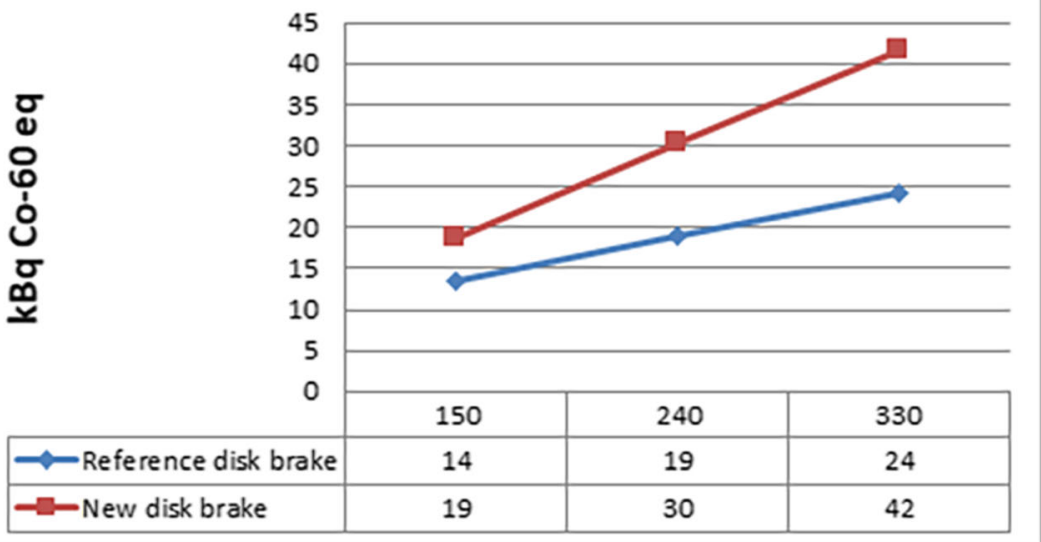

disc brake impact. Hence, a longer lifetime would not benefit the impact categories for the new disc brake. The longer lifetime seemed to have a 'break even' lifetime over $240,000 \mathrm{~km}$ where the impact of the reference disc brake gained a lower impact than the new disc brake, similarly as illustrated for 'water consumption' category in Fig. 8.

The sensitivity analysis of the lifetime showed that longer use time, over $240,000 \mathrm{~km}$, was not favourable for the new disc brake, in most impact categories. The reference disc brake had a better eco-profile than the new disc brake in most categories, regardless of if the use time was shorter or longer.

\section{Discussion}

The differences in impacts between the two disc brake alternatives were divided into the 17 impact categories. While nine categories showed an increased impact, eight impact categories displayed an impact reduction for the new disc brake, regardless of the LCA model. The most significant impacts were connected to material and manufacturing phases for both disc brakes. A significantly higher impact by the new disc brake was observed in the two impact categories of 'ionizing radiation' and 'mineral resource scarcity'. The sensitivity analysis showed that the difference in these impact categories, between the two disc brakes, would increase with a longer lifetime. One impact category, 'human carcinogenic toxicity', displayed a significant decrease in impact. In this category, a longer use time would not change the relative lower impact of the new disc brake, compared to the reference disc brake. The primary contributing impacts, depending on impact category, of the reference disc brake, were linked to the cast iron, the manufacturing of the discs, manufacture of pads, and copper and brass used in the pads friction mix.

The new disc brake contributing impacts were connected primarily to the tungsten carbide (WC) coating. A study of the Chinese WC production by Ma et al. (2017) calculated an energy requirement for the production of
Fig. 7 The 'human carcinogenic toxicity' impact difference was not changed by a longer lifetime

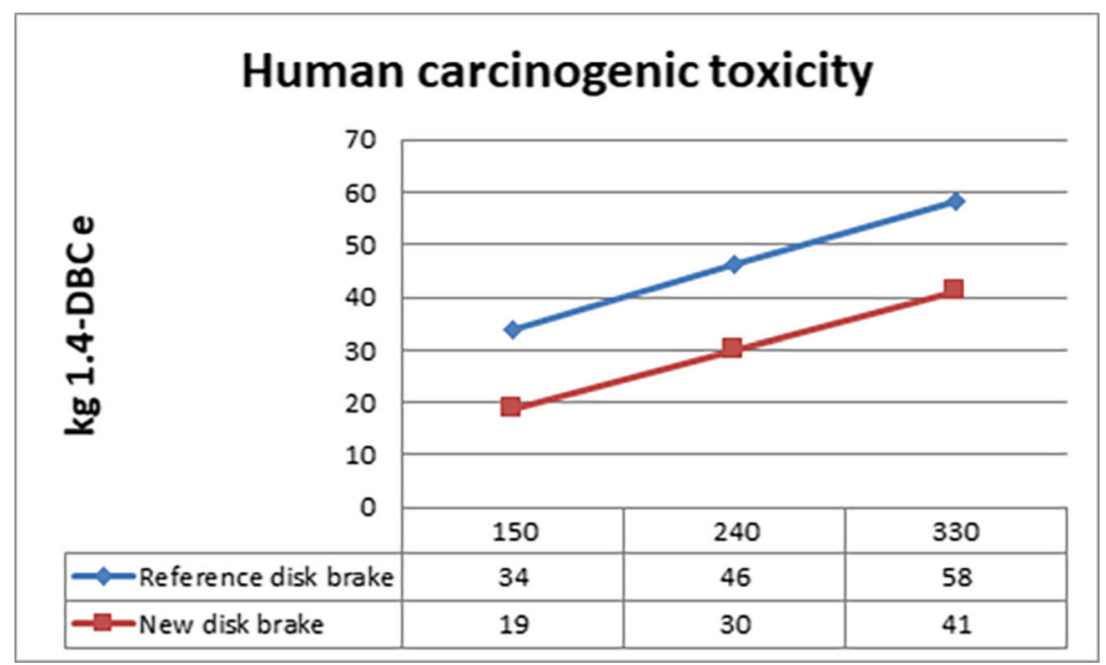


Fig. 8 The 'water consumption' impact category difference increases, and the impact of the reference disc brake gained a lower impact than the new disc brake, for a lifetime of over $240,000 \mathrm{~km}$

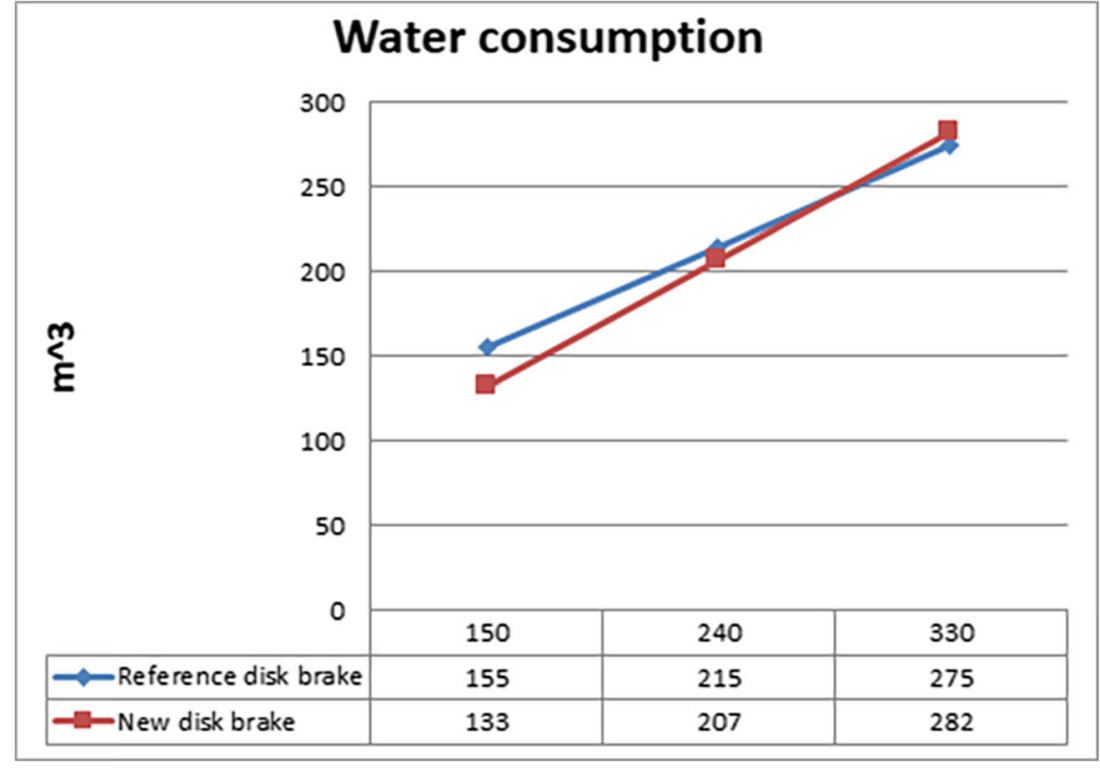

$1 \mathrm{~kg}$ tungsten carbide powder to $170 \mathrm{MJ}$-eq. In a recently presented article (Furberg et al. 2019), a non-Chinese production of $1 \mathrm{~kg}$ tungsten carbide powder was assessed to be 58 MJ-eq. These two studies used the ReCiPe 2008 method. This variability of tungsten carbide data implies that the impacts of the disc coating could be underestimated and could potentially overshadow any benefits. Caution should be taken during the interpretation of the results. It is not objective how the impacts of tungsten carbide processes can be compared to the benefits of more extended lifetime usage.

Excluding a significant impact such as the car body and all other use phase impacts than disc brake and exhaust emissions can seem to give misguiding results. It is noted that the complete car use environmental impacts are more significant than the disc brake emissions, by magnitudes. In this study, we aimed to focus on the emission due to braking, by excluding other use phase emissions, to highlight and investigate the disc brake emissions.

One of the concerns in omitting LCA parts was that there might be significant environmental impacts overlooked, especially in cases with no or few previous studies of a particular product. Analysis of the impact category magnitudes showed that between 0.1 and $48 \%$ of impacts were omitted through simplification. This means that although the differences between the impacts of the two discs were the same independent of the model the impact was harder to evaluate as significant or insignificant since the full impact was reduced. Contrary to this case, the reduction is usually an unknown amount. An analysis of both models and results showed that since the impact of, e.g. the cast iron disc of the new disc brake was omitted the impacts were naturally also missing. This lack is a severe issue if significant improvement parameters are overlooked or if an effort is put in ineffective actions.

According to the ILCD Handbook (European Commission 2010), all cut-off's of the inventory is entirely acceptable and has no consequences on the validity of the LCA, as the extent of the incompleteness is set in line with the goal and scope of the study. Hence, if it is possible to fulfil the purpose of the study, the similarity to the target is adequate. In this case study, the two disc brakes were assessed through two LCA models. Comparison of the results showed that the differences in impact between the products were identical regardless of the model. The same impact categories could be identified as being of interest when comparing the new disc brake to the reference disc brake. It was, however, more challenging to determine if an impact was significant or insignificant.

Note that the omitted parts, in this case, were minor. Therefore, the gains in minimising inventory data requirements by using the omission of identical parts method were minimal owing to the need to model the spare parts completely as full LCA models.

In a previous disc brake study, i.e. the conference paper (Gradin and Hedlund-Åström 2018), the omission of parts turned out not to be valid. This error was due to the different life length of the disc brake parts. Therefore, the spare parts need to be modelled fully not to risk false results. The excluded parts contributed to the most severe underestimation of the compared impacts mainly in the case of the cast iron disc. The result of the conference paper indicated quite correctly that the new disc brake demands more energy and resources during the material and manufacturing phases. However, since the spare part impacts were missing the comparison did not give a valid result. Even though the conference paper failed to 
present valid results, there were lessons to be learned. There is no expressed terminology for this simplification method; it is hard to find relevant published cases and the development of the methodology might be weakened. Therefore, it is beneficial to define a term for the method. This paper suggests naming the simplification method as comparative LCA with an omission of identical parts.

There is a lack of knowledge regarding non-exhaust disc brake emissions in LCA. Other published disc brake LCA studies, to compare this study to, cannot be found. This study attempted to highlight the non-exhaust emissions of the disc brake. These emissions will become more significant as low emission fuels and drivetrains are developed. The possibility to include not only exhaust emissions but also non-exhaust emissions connected to the operations phase was central in this study.

Future work is encouraged, in both the area of the environmental impact of disc brakes but also regarding simplification of comparative LCA through omission of identical parts. Additionally, there are needs to refine the modelling of PM emissions in LCA. Primarily connected to the unaddressed toxicity (Oberdörster et al. 2005), but also concerning the issue of how to model material specific PM emissions. It is of interest to expand the studies toward endpoint assessments, i.e. the life cycle impacts of disc brakes involving, e.g. human health issues and benefits. Through the study of the metric disability-adjusted life years (DALY), unit in years, the net positive, negative and neutral DALY can be determined for the disc brakes (Arvidsson et al. 2016). However, due to the unaddressed PM toxicity, the endpoint result might be underestimated.

\section{Conclusions}

The objective of the two LCA studies was to identify and analyse the difference in environmental impacts between two disc brakes: a new disc brake and a reference disc brake. Through a material change in the friction pad and coating of the disc, the amount of particulate emissions caused by the new disc brake could be diminished during the use phase. However, the raw material extraction and manufacturing phase upstream from the use phase were affected due to resource and energy needs of the new disc brake.

Additionally, the validity of a simplification method called 'comparative LCA with an omission of identical parts' was investigated. There is a lack of published research on comparative LCA and discussions around the methodology of simplifications. The validity of the LCA model was investigated by comparing results between the simplified and the full LCA of the disc brakes. The impact differences were identical independent of the LCA model. Hence, the purpose of the study could be fulfilled, and the simplified model results were valid.
It was, however, more challenging to determine if an impact was significant or insignificant.

Both LCA models, of the new disc brake and the reference disc brake, revealed that the new disc brake had limited advantages. The new disc brake alternative used more resources during the manufacture of one disc compared to the reference disc brake. The shorter life length of the reference disc resulted in a higher demand on the number of spare part discs to fulfil the same functional unit, but this impact was reduced due to material recycling. The sensitivity analysis of the lifetime showed that longer use time, over $240,000 \mathrm{~km}$, was not favourable for the new disc brake, in most impact categories.

Caution must be observed during the interpretation of the results concerning the potentially underestimated impacts of the tungsten carbide used in the new disc coating. The underestimation could potentially undo any benefit of the new disc brake.

This study can unfortunately not be compared with other studies since other published LCA studies of disc brakes are not available. Hopefully, this study can support future LCA studies on disc brakes.

Acknowledgements Open access funding provided by Royal Institute of Technology. The research leading to these results received funding from the European Union's Horizon 2020 research and innovation programme under grant agreement No. 636592 (LOWBRASYS project). The authors would like to thank Anne-Marie Tillman and Anna Björklund for valuable comments concerning the study and manuscript.

\section{Compliance with ethical standards}

Conflict of interest The authors declare that they have no conflict of interest.

Open Access This article is distributed under the terms of the Creative Commons Attribution 4.0 International License (http:// creativecommons.org/licenses/by/4.0/), which permits unrestricted use, distribution, and reproduction in any medium, provided you give appropriate credit to the original author(s) and the source, provide a link to the Creative Commons license, and indicate if changes were made.

\section{References}

Abbasi S, Jansson A, Sellgren U, Olofsson U (2013) Particle emissions from rail traffic: a literature review. Crit Rev Environ Sci Technol 43:2511-2544. https://doi.org/10.1080/10643389.2012.685348

Andersson C, Dettmann T (2013) Environmental footprint and performance analysis of a brake disc production line using discrete event simulation. Chalmers University of Technology

Arvidsson R, Hildenbrand J, Baumann H, Islam KMN, Parsmo R (2016) A method for human health impact assessment in social LCA: lessons from three case studies. Int J Life Cycle Assess 23:690-699. https://doi.org/10.1007/s11367-016-1116-7

Capitano K (2015) Methodologies for life cycle assessment of passenger vehicles. ProQuest Diss Theses 120 
Eddy DC, Krishnamurty S, Grosse IR, Wileden JC, Lewis KE (2015) A predictive modelling-based material selection method for sustainable product design. J Eng Des 26:365-390. https://doi.org/10. 1080/09544828.2015.1070258

Ekvall T, Assefa G, Björklund A, Eriksson O, Finnveden G (2007) What life-cycle assessment does and does not do in assessments of waste management. Waste Manag 27:989-996. https://doi.org/10.1016/j. wasman.2007.02.015

European Commission (2010) International reference life cycle data system (ilcd) handbook - general guide for life cycle assessment - detailed guidance. Luxembourg. https://doi.org/10.2788/38479

Federici M, Menapace C, Moscatelli A, Gialanella S, Straffelini G (2016) Effect of roughness on the wear behavior of HVOF coatings dry sliding against a friction material. Wear 368-369:326-334. https:// doi.org/10.1016/j.wear.2016.10.013

Finnveden G (1999) Methodological aspects of life cycle assessment of integrated solid waste management systems. Resour Conserv Recycl 26:173-187. https://doi.org/10.1016/S0921-3449(99) 00005-1

Finnveden G, Hauschild MZ, Ekvall T, Guinée JB, Heijungs R, Hellweg S, Koehler A, Pennington D, Suh S (2009) Recent developments in life cycle assessment. J Environ Manag 91:1-21. https://doi.org/10. 1016/j.jenvman.2009.06.018

Furberg A, Arvidsson R, Molander S (2019) Environmental life cycle assessment of cemented carbide (WC-Co) production. J Clean Prod 209:1126-1138. https://doi.org/10.1016/j.jclepro.2018.10.272

Google (2018) Google maps [WWW Document]. URL https://www. google.com/maps. Accessed 5.9.18

Gradin KT, Hedlund-Åström A (2018) Comparative life cycle assessment of vehicle disc brakes, in: EuroBrake 2018. Fisita, Haag

Gradin KT, Luttropp C, Björklund A (2013) Investigating improved vehicle dismantling and fragmentation technology. J Clean Prod 54: 23-29. https://doi.org/10.1016/j.jclepro.2013.05.023

Grigoratos T, Martini G (2015) Brake wear particle emissions: a review. Environ Sci Pollut Res 22:2491-2504. https://doi.org/10.1007/ s11356-014-3696-8

Harada N, Takuma M, Tsujikawa M, Higashi K (2013) Effects of V addition on improvement of heat shock resistance and wear resistance of Ni-Cr-Mo cast steel brake disc. Wear 302:1444-1452. https://doi.org/10.1016/j.wear.2013.01.029

Hauschild MZ, Rosenbaum RK, Olsen SI (2018) Life cycle assessment theory and practice. Springer. https://doi.org/10.1007/978-3-31956475-3

Hawkins TR, Gausen OM, Strømman AH (2012) Environmental impacts of hybrid and electric vehicles - a review. Int J Life Cycle Assess 17: 997-1014. https://doi.org/10.1007/s11367-012-0440-9

Hawkins TR, Singh B, Majeau-Bettez G, Strømman AH (2013) Comparative environmental life cycle assessment of conventional and electric vehicles. J Ind Ecol 17:53-64. https://doi.org/10.1111/j. 1530-9290.2012.00532.x

Heijungs R, Henriksson PJG, Guinée JB (2017) Pre-calculated LCI systems with uncertainties cannot be used in comparative LCA. Int $\mathrm{J}$ Life Cycle Assess 22:461. https://doi.org/10.1007/s11367-0171265-3

IEA (2016) Hungary - Energy System Overview

IIASA (2016) Impacts reducing air pollution worldwide

ISO (2006) ISO 14040:2006. Environmental management: life cycle assessment, principles and framework

Koffler C, Rohde-Brandenburger K (2010) On the calculation of fuel savings through lightweight design in automotive life cycle assessments. Int J Life Cycle Assess 15:128-135. https://doi.org/10.1007/ s11367-009-0127-z
Kupiainen KJ (2007) Road dust from pavement wear and traction sanding LOWBRASYS (2017) LOWBRASYS project [WWW Document]. URL http://www.lowbrasys.eu/en. Accessed 6.1.17

Ma X, Qi C, Ye L, Yang D, Hong J (2017) Life cycle assessment of tungsten carbide powder production: A case study in China. J Clean Prod 149:936-944. https://doi.org/10.1016/j.jclepro.2017. 02.184

Madeswaran A, Natarajasundaram B, Ramamoorthy B (2016) Reformation of Eco-Friendly Automotive Brake Pad by Using Natural Fibre Composites. SAE Tech Pap 7. https://doi.org/10. 4271/2016-28-0164

Maleque MA., Dyuti S, Rahman MM (2010) Material Selection method in design of automotive brake disc. Proc. World Congr. Eng. 2010 III, 5. https://doi.org/2078-0958

Notter D, Gauch M, Widmer R, Wäger P, Stamp A, Zah R, Althaus HJ (2010) Contribution of Li-ion batteries to the environmental impact of electric vehicles. Environ Sci Technol 44:6550-6656. https://doi. org/10.1021/es903729a

Ntziachristos L, Boulder P (2016) 1.A.3.b.vi Road transport: Automobile tyre and brake wear 1.A.3.b.vii Road transport: automobile road abrasion contents. EMEP/EEA air Pollut. Emiss. Invent. Guideb. 2016

Oberdörster G, Maynard A, Donaldson K, Castranova V, Fitzpatrick J, Ausman K, Carter J, Karn B, Kreyling W, Lai D, Olin S, MonteiroRiviere N, Warheit D, Yang H (2005) Principles for characterizing the potential human health effects from exposure to nanomaterials: elements of a screening strategy. Part Fibre Toxicol 2:8. https://doi. org/10.1186/1743-8977-2-8

Perricone G, Alemani M, Metinöz I, Matějka V, Wahlström J, Olofsson U (2017) Towards the ranking of airborne particle emissions from car brakes - a system approach. Proc Inst Mech Eng D J Automob Eng 231:781-797. https://doi.org/10.1177/0954407016662800

Perricone G, Alemani M, Wahlström J, Olofsson U (2019) A proposed driving cycle for brake emissions investigation for test stand. Proc Inst Mech Eng D J Automob Eng. https://doi.org/10.1177/ 0954407019841222

PRe Consultants (2017) SimaPro 8 Developer

PRé Consultants (2019) SimaPro 9 Developer

Ridge L (1998) SAE TECHNICAL EUCAR - Automotive LCA Guidelines - Phase 2

Schmidt W-P, Dahlqvist E, Finkbeiner M, Krinke S, Lazzari S, Oschmann D, Pichon S, Thiel C (2004) Life cycle assessment of lightweight and end-of-life scenarios for generic compact class passenger vehicles. Int J Life Cycle Assess 9:405-416. https://doi.org/ 10.1065/lca2004.09.174

Tillman A-M (2000) Significance of decision-making for LCA methodology. Environ Impact Assess Rev 20:113-123. https://doi.org/10. 1016/S0195-9255(99)00035-9

Tillman A-M, Ekvall T, Baumann H, Rydberg T (1994) Choice of system boundaries in life cycle assessment. J Clean Prod 2:21-29

Verma PC, Alemani M, Gialanella S, Lutterotti L, Olofsson U, Straffelini G (2016) Wear debris from brake system materials: a multianalytical characterization approach. Tribol Int 94:249-259. https://doi.org/10.1016/j.triboint.2015.08.011

Wahlström J, Lyu Y, Matjeka V, Söderberg A (2017) A pin-on-disc tribometer study of disc brake contact pairs with respect to wear and airborne particle emissions. Wear 384-385:124-130. https:// doi.org/10.1016/j.wear.2017.05.011

Weymar E, Finkbeiner M (2016) Statistical analysis of empirical lifetime mileage data for automotive LCA. Int J. Life Cycle Assess 21:215223. https://doi.org/10.1007/s11367-015-1020-6

Publisher's note Springer Nature remains neutral with regard to jurisdictional claims in published maps and institutional affiliations. 